\title{
Agroecological service crops managed with roller crimper reduce weed density and weed species richness in organic vegetable systems across Europe
}

\author{
David Navarro-Miró ${ }^{1}$ (D ) José M. Blanco-Moreno ${ }^{1} \cdot$ Corrado Ciaccia $^{2} \cdot$ Lourdes Chamorro $^{1} \cdot$ Elena Testani ${ }^{2}$. \\ Hanne Lakkenborg Kristensen ${ }^{3} \cdot$ Margita Hefner $^{3} \cdot$ Kalvi Tamm $^{4}$ • Ingrid Bender ${ }^{5}$ Manfred Jakop ${ }^{6} \cdot$ Martina Bavec $^{6}$. \\ Hélène Védie $^{7} \cdot$ Lìga Lepse $^{8} \cdot$ Stefano Canali $^{2} \cdot$ F. Xavier Sans ${ }^{1}$
}

Accepted: 22 September 2019 / Published online: 18 November 2019

(C) INRA and Springer-Verlag France SAS, part of Springer Nature 2019

\begin{abstract}
Agroecological service crops are introduced into the vegetable crop rotation to provide agroecosystem services, and are a key strategy for weed management in organic systems. Organic farmers across Europe usually terminate these crops before cultivation of the subsequent cash crop, using them as green manure. Recently, the in-line tillage-roller crimper has attracted interest across Europe. It allows flattening the agroecological service crops and creates a narrow furrow that facilitates the fertilization and transplantation of organic vegetables. In Europe, most of the research on this technology has been carried out in Italy, and no studies are available analyzing its effect on weed density, weed species richness, and community composition in different vegetable crops, soils, and climatic conditions across Europe. We compared the effects of the usage of in-line tillage-roller crimper versus green manure on the weed abundance, species richness, and community composition in fourteen original datasets from five countries over 2 years. The support for a common effect of in-line tillage-roller crimper across trials was tested by means of a meta-analytic approach based on a weighted version of Stouffer's method. Our results indicate that in-line tillageroller crimper management reduced weed density by $35.1 \%$ on average in comparison with green manure, and this trend was significant across trials. Moreover, we document a significant reduction of weed species richness under this technique and significant but, in general, minor changes in the weed community composition across the trials. Therefore, this study provides for the first time a solid evidence of the effectiveness of this management technique to reduce weed density at the early stages of crop growth across a wide range of vegetable systems and production conditions in Europe. Nonetheless, it is important to note that the effect of this technology can be strongly affected by variations in cropping conditions.
\end{abstract}

Keywords Agroecological service crops $\cdot$ In-line tillage $\cdot$ Mulch $\cdot$ Community composition

David Navarro-Miró

david.danami@gmail.com

1 Agroecosystems Research Group; Biodiversity Research Institute (IRBio); and Section of Botany and Mycology, Department of Evolutionary Biology, Ecology and Environmental Sciences, Faculty of Biology, University of Barcelona, Av. Diagonal 643, 08028 Barcelona, Spain

2 Council for Agricultural Research and Economics, Research Centre for Agriculture and Environment (CREA-AA), Rome, Italy

3 Department of Food Science, Aarhus University, Aarhus, Denmark
4 Department of Agrotechnology, Estonian Crop Research Institute, Jõgeva, Estonia

5 Department of Jõgeva Plant Breeding, Estonian Crop Research Institute, Jõgeva, Estonia

6 Institute for Organic Farming, Faculty of Agriculture and Life Sciences, University of Maribor, Ho??e, Maribor, Slovenia

7 Groupe de Recherche en Agriculture Biologique (GRAB), Avignon, France

8 Institute of Horticulture, Latvian University of Agriculture, Dobeles novads, Latvia 


\section{Introduction}

Agroecological service crops (ASCs) are sown in cropping systems to provide or promote agroecosystem services, independent of their position in the crop rotation and the method used to terminate them. This term includes catch crops, cover crops, and complementary crops (Canali et al. 2015). In vegetable systems, ASCs are usually grown during the cold rainy season. However, some authors have also highlighted the potential applicability of summer ASCs in southern Mediterranean regions of Europe, although their implementation is still limited (Canali et al. 2015).

In organic systems, ASCs are considered a key strategy for managing weeds (Gallandt 2014). To this end, numerous organic producers terminate the ASCs before the subsequent cash crop to avoid competition and reduce weed emergence. Nevertheless, some authors have noted that weed control effectiveness strongly depends on the termination technique selected (Canali et al. 2013; Ciaccia et al. 2016). Among European organic farmers, the most widespread management technique consists of chopping the ASCs and incorporating them into the soil by noninversion tillage (but sometimes plowing) as green manure (GM), while no-till methods are hardly used (Peigné et al. 2016). Despite the benefits of no-till practices for improving the quality of the soil (Sapkota et al. 2012), their adoption in organic systems is still limited because of important constraints mainly related to weed control (Casagrande et al. 2016).

However, in recent years, the no-till roller crimper (RC) for ASC management has attracted the interest of organic farmers and researchers across Europe (Casagrande et al. 2016; Vincent-Caboud et al. 2017). The RC allows flattening of the ASCs and creates a dense layer of plant residues (i.e., mulch) connected to the soil by the roots. The presence of mulch has physical and chemical effects, which can limit weed germination and seedling emergence. It has been shown that the extracts of some ASC species residues inhibit weed germination both in bioassays and open-field conditions (Ciaccia et al. 2015). The physical effect of the mulch might reduce weed density both by modifying the environmental conditions of the soil surface and by acting as a physical barrier that obstructs the development of the seedlings (Altieri et al. 2011). The flattened ASC modifies the soil temperature, surface daily temperature range, and soil water content (Altieri et al. 2011; Canali et al. 2013), which affects weed potential germination (Guillemin et al. 2013). Additionally, it reduces the light intensity that arrives at the soil surface (Teasdale and Mohler 2000), affecting the dormancy release and germination of many weed species (Batlla and Benech-Arnold 2014). Weed germination and emergence is also strongly conditioned by the mulch biomass and the specific weather conditions (i.e., temperature, rainfall) of the year. In general, the quantity of residues is more important than the type of residues, and the increase of the mulch biomass present on the soil surface decreases weed emergence exponentially (Teasdale and Mohler 2000). The specific weather conditions of the year can have an influence on both the ASC biomass production and the potential subsequent weed germination and emergence during the cash crop production (Carr et al. 2012; Canali et al. 2013).

Opposite results have been observed for the effect of mulch on weed species richness (Campiglia et al. 2010; Radicetti et al. 2013). Similarly, it is unclear how physical and allelopathic effects of mulch determine which species can germinate and emerge (Moonen and Bàrberi 2004). Mirsky et al. (2012) suggested that weed control by the mulch is species-specific and depends on both the sufficient quantity of mulch when a species is germinating and the energy reserves of propagules (i.e., big versus small seeds). Conversely, Campiglia et al. (2010) affirmed that the mulch acts to a greater extent on the number of individual plants irrespective of weed species. Furthermore, it is also important to note that some studies have reported shifts in the weed community composition in response to mulch presence (Campiglia et al. 2010; Radicetti et al. 2013).

The limited implementation and research on the no-till $\mathrm{RC}$ approach might be related to the predominant humid temperate climate of Europe (Mäder and Berner 2012). Additionally, in vegetable cropping systems, some agronomic difficulties, such as transplanting and fertilization of the vegetable crop, have hindered the adoption of this technique by organic famers (Luna et al. 2012; Canali et al. 2013). To overcome these limitations and facilitate the adaptation of this technology to organic European vegetable systems, the RC was modified by adding inline tillage (in-line tillage/roller crimper, hereafter ILRC) (Canali et al. 2013). This modification, based on vertical sharpened discs and coulters arranged in line at the rear of the RC, allows flattening the ASC and simultaneously creating a narrow transplanting furrow without disturbing the surrounding mulch (Fig. 1).

Since its development, the research has mainly focused on analyzing the effect of cold rainy season ASCs managed with ILRC on weed abundance in zucchini and melon cash crops, and all these experiments have been carried out in the longterm MOVE trial located in Italy (Canali et al. 2013; Ciaccia et al. 2015, 2016). Moreover, most of the research focused on flattening the ASCs has been mainly focused on optimizing the RC design, selecting the best cold rainy season ASC composition, identifying changes in the abundance of perennial species, and analyzing the effect on cash crop development 


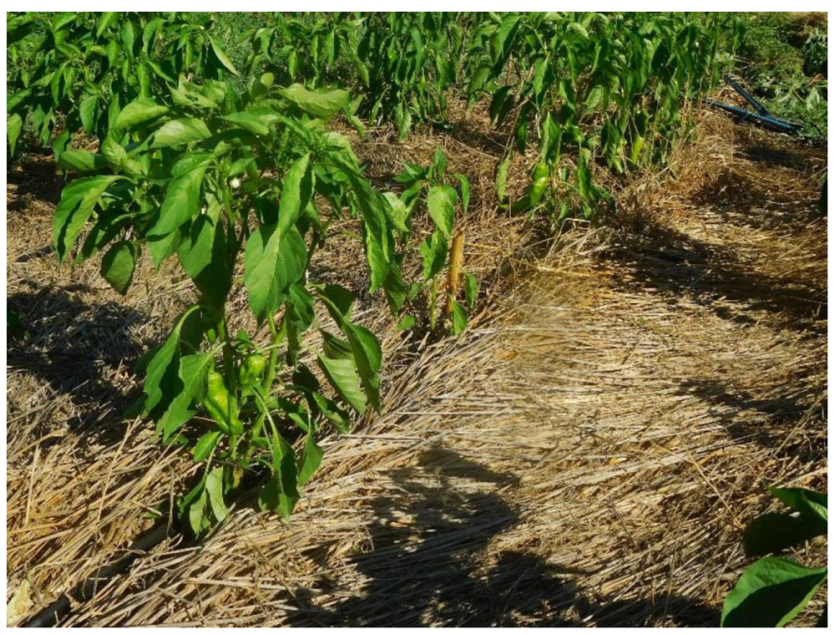

Fig. 1 Pepper plant transplanted into a narrow furrow created by the ILRC after flattening the ASCs in Spain. Author: Alejandro Pérez-Ferrer

and production (Mirsky et al. 2012; Carr et al. 2012; Canali et al. 2013; Frasconi et al. 2019). However, to the best of our knowledge, only one study has focused on the effect of RC management on weed species richness (Halde et al. 2015), and another one has discussed, but not tested, its influence on weed community composition (Ciaccia et al. 2016). It therefore appears that the currently available information does not yet show robust evidence of the effectiveness of ILRC for weed control and the effect of this management technique on weed species richness and community composition across different vegetable crops, soils, and climatic conditions in European organic vegetable systems.

To fill this knowledge gap and investigate the potential for a wider adoption of this technology, this study aims to evaluate whether ASC management (GM vs. ILRC) affects the structural parameters of weed assemblages (weed density, species richness, and community composition). Moreover, we also evaluate the magnitude of the effects of ILRC compared with those of GM, and whether this effect is reliable or, on the contrary, depends on the variations in cropping conditions, and the ASC biomass produced. For these purposes, we analyzed fourteen original datasets on weed assemblages from five European countries over 2 years. The datasets are the result of a joint effort within the framework of the SoilVeg project, which aimed to analyze the applicability of ILRC to European vegetable agroecosystems. We hypothesized that (i) ILRC reduces weed density and species richness and modifies the community composition in comparison with GM ASC management, and (ii) the benefits of ILRC are strongly affected by variations in cropping conditions caused by interannual deviations in weather and in timing and effectiveness of field operations, as well as differences in relation to changing the area within the field. However, since we have not investigated these factors in detail, we consider that differences between years summarize these effects.

\section{Materials and methods}

\subsection{Locations and trials}

The organic vegetable field trials were located in Denmark (DK), Estonia (EE), Italy (IT), Slovenia (SI), and Spain (ES) for two consecutive years (Table 1). The locations were selected to cover a wide range of vegetable production conditions under different climatic zones of Europe (Metzger 2005). The trial established in DK represents the Atlantic North European climatic zone under the influence of the Atlantic Ocean, and it is characterized by cold winters and mild summers. The EE trial was located in the Nemoral zone, which is characterized by late spring and summer with high temperatures and abundant precipitation. The trial of SI represents the Alpine South zone characterized by the environmental conditions of the high mountains. The trials of ES and IT were located in the Mediterranean North zone, characterized by winters with maximum precipitation events and dry summers.

All partners (DK, EE, IT, SI, ES) grew the ASCs in the cold rainy season followed by a spring-summer cash crop. In parallel trials, in the Mediterranean countries (IT and ES), summer ASCs (warm-dry season) were also cultivated before the autumn-winter cash crop. Herein, IT-SCC and ES-SCC are used to refer to the main trials, and IT-ACC and ES-ACC are used for the parallel trials. Thus, in total, fourteen original datasets were analyzed (i.e., seven field experiments during two consecutive years) (Table 1).

\subsection{Experimental design, management, and sampling methods of each trial}

Cash crop management varied among partners depending on the climatic conditions, available machinery, and requirements of the selected vegetable crop. The experiment was repeated on the same plots in both years in ES. In all the other trials, the plots were moved to an adjacent area of the same experimental field. Each partner had a different experimental layout and management, but the comparison between ASCs' management was common to all (ILRC vs. GM). ILRC management consists of (i) several rapid passes of a roller crimper to flatten the ASCs, followed by (ii) a slower operation with an ILRC to create a narrow transplanting furrow without disturbing the surrounding mulch. GM management comprises (i) mowing-chopping the ASCs; (ii) incorporating ASCs into the soil by tillage, when the plant residues were dry; and (iii) seedbed preparation.

Each partner assessed weed and ASC species abundance at an early stage of the cash crop. Both germinated and resprouting individuals were counted and identified at the species level prior to weeding operations. These data provided measures of weed density and weed species richness. Weed density (individuals $\mathrm{m}^{-2}$ ) comprised the total number of 


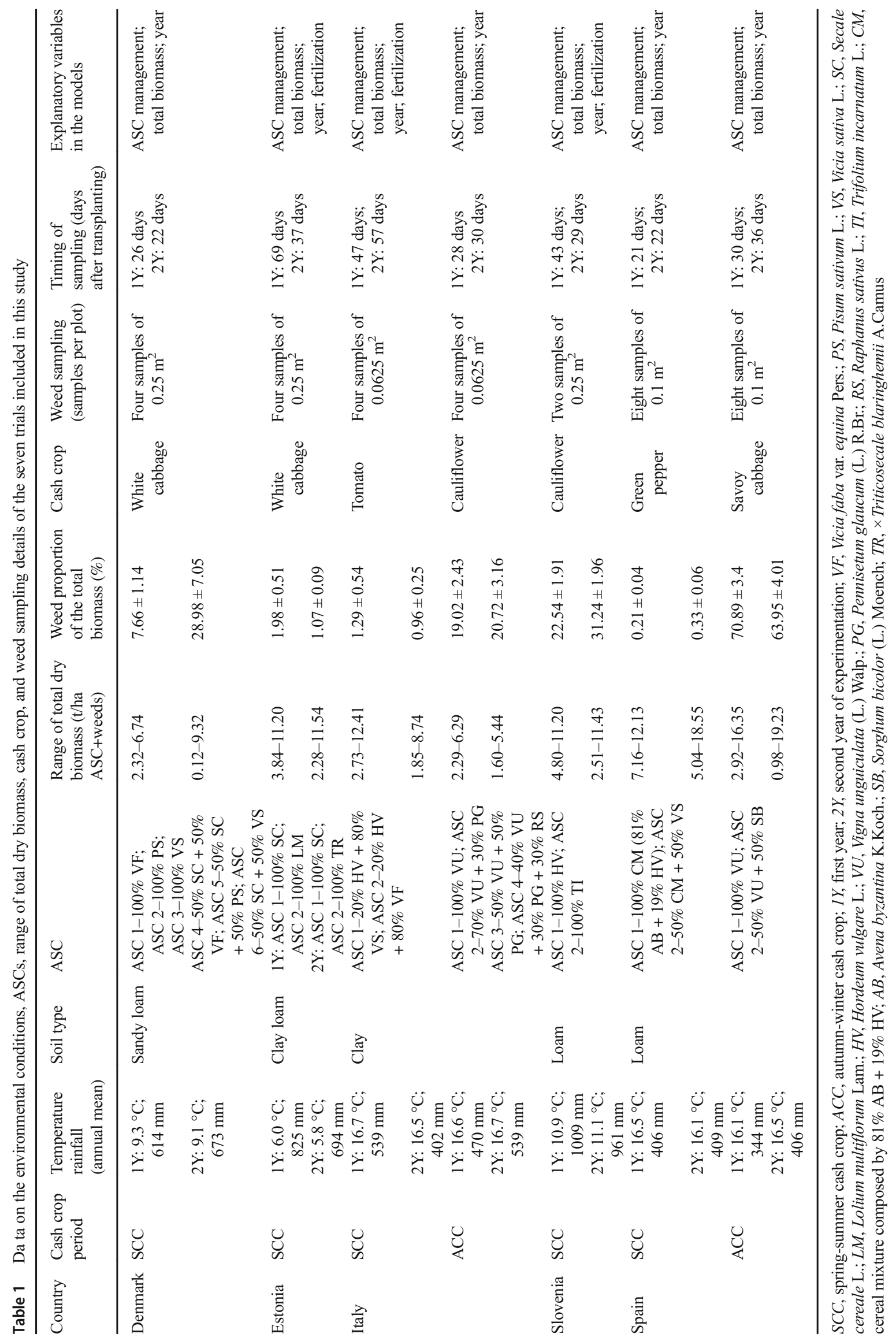


germinated and resprouting individuals, including weed and ASC species, to account for all the potential competition towards cash crops. On the other hand, weed species richness (number of species/sample) and community composition referred exclusively to weeds germinated at the beginning of the cash crop. In these cases, we analyzed exclusively germinated weeds to isolate the response of weed communities to the different ASC management methods. Weed species abundances were averaged for each plot in all trials, except in ES where the exact locations of samples were taken into account (see below). Weed species richness cannot be standardized to fixed surface and therefore, in each trial, weed species richness referred to the sampling frame.

Specific information on the environmental conditions (i.e., annual mean temperature and rainfall, soil texture), ASC composition, range of total dry biomass, cash crop grown, and weed sampling procedure of the seven trials included in this study is detailed in Table 1.

\subsubsection{Denmark}

The field experiment was conducted at the research center of the Department of Food Science of Aarhus University located in Årslev (Denmark) $\left(10^{\circ} 27^{\prime} \mathrm{E} ; 55^{\circ} 18^{\prime} \mathrm{N}\right)$. The trial was newly established and the previous crop grown in the area was barley (Hordeum vulgare L.). The trial was established on a sandy loamy soil with a $1 \%$ carbon in the $0-0.5-\mathrm{m}$ soil layer. The trial had a split-plot randomized complete block experimental design with three replicates, where ASC management (i.e., ILRC vs. GM) was the whole-plot factor, while ASC composition was the subplot factor (i.e., six different ASC compositions) (Table 1). The plot size was $3.2 \mathrm{~m} \times 10 \mathrm{~m}$ during the first year and $4.8 \mathrm{~m} \times 10 \mathrm{~m}$ during the second year. White cabbage (Brassica oleracea var. capitata L.) was transplanted on July 1, 2016, and on June 21, 2017. The harvest was carried out on November 11, 2016, and on November 2, 2017. During the first year, all the plots were fertilized prior the ASC plantation (October 5, 2015) with feather meal pellets (26 $\mathrm{kg} \mathrm{N} \mathrm{ha}^{-1}$ ) and during the cabbage development $\left(50 \mathrm{~kg} \mathrm{~N} \mathrm{ha}^{-1}\right.$ ) (August 25, 2016). Cash crop was irrigated two times, on August and September, with sprinklers. During the second year, plots were fertilized with feather meal $\left(26 \mathrm{~kg} \mathrm{~N} \mathrm{ha}^{-1}\right.$ ) prior to the ASC plantation (October 9, 2016), a week before the cabbage transplantation with feather meal pellets $\left(100 \mathrm{~kg} \mathrm{~N} \mathrm{ha}^{-1}\right)$ and lupine seeds $\left(30 \mathrm{~kg} \mathrm{~N} \mathrm{ha}^{-1}\right)$, and during the cabbage development with feather meal pellets (80 $\mathrm{kg} \mathrm{N} \mathrm{ha}^{-1}$ ) (August 24, 2017). In this cash crop cycle, no irrigation was required. Weeds were evaluated in $0.5 \mathrm{~m} \times$ $0.5 \mathrm{~m}$ quadrats randomly distributed on each plot, and one cabbage plant was included in each quadrat. In 2016, weeds were sampled 26 days after transplanting, while in 2017, the sampling was carried out 22 days after transplanting.

\subsubsection{Estonia}

The field experiment was conducted at the experimental organic research field in eastern Estonia at Jõgeva (Estonia) $\left(58^{\circ} 44^{\prime} \mathrm{N} ; 26^{\circ} 24^{\prime} \mathrm{E}\right)$. The trial was newly established on a certified organic area since 2005. Previously, the area was used for organic arable crop experimentation. Specifically, the previous crop grown was red clover (Trifolium pratense L.). The experimental field was located on a clay loamy soil with a $3 \%$ organic carbon. The experimental design was a strip-plot design with ASC strips and ASC management crossed with the fertilizing factor (i.e., manure vs. without manure), and three replicates per treatment. The plot size was $6 \mathrm{~m} \times 4 \mathrm{~m}$. White cabbage was transplanted in the first year from the 13th to the 16th of June 2016, and in the second year on June 19, 2017. The harvest was carried out on October 7, 2016, and from October 4 to 6 in 2017. Plots belonging to the fertilization treatment were fertilized before the ASC plantation with the application of $30 \mathrm{t} / \mathrm{ha}$ solid cattle manure (153 $\mathrm{kg} \mathrm{ha}^{-1} \mathrm{~N}, 57 \mathrm{~kg} \mathrm{ha}^{-1} \mathrm{P}$, and $81 \mathrm{~kg} \mathrm{ha}^{-1} \mathrm{~K}$ ). During the second year, all plots were fertilized with $12 \mathrm{tha}^{-1}$ of horse manure compost $\left(12 \mathrm{~kg} \mathrm{ha}^{-1} \mathrm{~N}, 1.2 \mathrm{~kg} \mathrm{ha}^{-1} \mathrm{P}\right.$, and $4.8 \mathrm{~kg} \mathrm{ha}^{-1}$ $\mathrm{K})$. During the first year, cash crop was not irrigated. Conversely, during the second year, all plants were watered one time in mid-July with a humic solution $\left(0.0003 \mathrm{~kg} \mathrm{ha}^{-1} \mathrm{~N}\right.$, $\left.0.0001 \mathrm{~kg} \mathrm{ha}^{-1} \mathrm{P}, 0.0002 \mathrm{~kg} \mathrm{ha}^{-1} \mathrm{~K}\right)$. Weeds were evaluated in $0.5 \mathrm{~m} \times 0.5 \mathrm{~m}$ quadrats in each plot, placed at $0.5 \mathrm{~m}$ from plot borders. During the first year, weeds were sampled 69 days after transplanting, while in the second year, the sampling was carried out 37 days after transplanting.

\subsubsection{Italy}

The field experiment was conducted in the Experimental Farm of Metaponto belonging to the Consiglio per la Ricerca in Agricoltura e l'Analisi dell'Economia Agraria in Southern Italy $\left(40^{\circ} 24^{\prime} \mathrm{N} ; 16^{\circ} 48^{\prime} \mathrm{E}\right)$. Both parallel field experiments (i.e., spring-summer cash crop (SCC) and autumn-winter cash crop (ACC)) were newly established. The previous crop grown was wheat (Triticum aestivum L.) in the ACC trial and fennel (Foeniculum vulgare Mill.) in the SCC trial. Soil texture was clay loam and contained on average $1.1 \%$ of organic carbon. In both trials, the plot size was $6 \mathrm{~m} \times 4 \mathrm{~m}$. Weed samplings were carried out in four $0.25 \mathrm{~m} \times 0.25 \mathrm{~m}$ quadrats randomly distributed in each plot in both trials.

Spring-summer cash crop The experimental design was a split-split-plot with main plots arranged as a randomized complete block design, with three factors and three replications. The main plot was assigned to the ASC factor (i.e., two ASC compositions), the subplot to the ASC management (GM vs. ILRC), and the split-plot to the fertilization factor (three levels). The fertilization factor consisted in (i) no fertilizer, 
(ii) commercial organic mineral fertilizer allowed in organic farming, and (iii) anaerobic digestate from cattle residues. The tomato (Solanum lycopersicum L.) was transplanted on April 28, 2016, and on May 5, 2017, and harvested from July 7 to August 25 in 2016, and from July 18 to August 25 in 2017. Crop was drip-irrigated weekly. Weed sampling was carried out 47 days after transplanting in the first year, and 57 days after the cash crop transplanting in the second year.

Autumn-winter cash crop The experimental layout was a splitplot with main plots arranged as a randomized complete block design, with two factors and three replications. The main plot was assigned to the ASC composition (four levels) (Table 1) and the subplot was assigned to the ASC management factor levels with two levels (GM vs. ILRC). The ASC was grown in the warm/dry season, followed by cauliflower (Brassica oleracea var. botrytis L.) as cash crop, which was transplanted on August 3 of both years. The cauliflower harvest was from November 23 to December 15 in 2015, and on November 28, 2016. No fertilization was applied before the ASC sowing. Off-farm animal manure-based organic fertilizer was applied just before the ASC termination, while the second was applied localized on the cauliflower plants during the cash crop plant development. The total fertilizer rate was $150 \mathrm{~kg} \mathrm{ha}^{-1} \mathrm{~N}$, $450 \mathrm{~kg} \mathrm{ha}^{-1} \mathrm{P}_{2} \mathrm{O}_{5}$, and $150 \mathrm{~kg} \mathrm{ha}^{-1} \mathrm{~K}_{2} \mathrm{O}$. ASC and cauliflower crops were irrigated on both years of experimentation by micro-sprinklers. ASC was irrigated on the emergence, while cauliflower was watered according to crop requirements each year. Weed sampling was performed in the first year 28 days after transplanting, while in the second year 30 days after transplanting.

\subsubsection{Slovenia}

The field experiment was conducted at the University of Maribor (Pivola), Faculty of Agriculture and Life Sciences (UM), Slovenia $\left(46^{\circ} 30^{\prime} \mathrm{N} ; 15^{\circ} 37^{\prime} \mathrm{E}\right)$. The trial was newly established in a field in which barley was produced the year before. The soil was characterized by a loam texture with an average of $2.66 \%$ of organic carbon in the $0-0.30$-m soil layer. The experimental design was a split-split-plot with plots arranged as a randomized complete block design, with three factors (i.e., ASC composition, ASC management, and fertilization) and four repetitions. ASC composition had two levels (Table 1), ASC management had two levels (GM vs. ILRC), and the fertilization factor had two levels (i.e., application of $30 \mathrm{t} \mathrm{ha}^{-1}$ of livestock manure before sowing ASC vs. without manure application). The plot size was $2.5 \mathrm{~m} \times 2.5 \mathrm{~m}$. Cauliflower was transplanted in the first year on June 3, 2016, and on May 24, 2017, and harvested on September 29, 2016, and September 5, 2017. During both years of experimentation, all plots were fertilized two times during the cash crop cycle using organic amendments. The first application was carried out at the cash crop transplanting $\left(70 \mathrm{~kg} \mathrm{ha}^{-1}\right.$ $\mathrm{N})$, while the second fertilization $\left(70 \mathrm{~kg} \mathrm{ha}^{-1} \mathrm{~N}\right)$ was performed during the development of the cash crop. Irrigation was required in the second year of experimentation two times during the cash crop development. Weeds were sampled in four $0.5 \mathrm{~m} \times 0.5 \mathrm{~m}$ quadrats randomly placed in each plot. In the first year, weeds were sampled 43 days after transplanting, while in the second year, 29 days after transplanting.

\subsubsection{Spain}

Spring-summer cash crop and autumn-winter cash crop Field experiments were conducted at the Gallecs Area of Natural Interest (Barcelona, Spain) $\left(41^{\circ} 33^{\prime} \mathrm{N} ; 2^{\circ} 12^{\prime} \mathrm{E}\right)$. The trial was newly established in an area which began the conversion to organic farming in 2005. The previous crop grown in the area was wheat. The trials were characterized by loamy soil texture and the mean proportion of organic carbon is $0.95 \%$. In both parallel trials (i.e., SCC and ACC), the experimental design was a randomized strip-plot with two factors (the ASC composition and ASC management) (Table 1) and four replicates. The different treatments were established in parallel bands randomly distributed, and four plots of $6 \mathrm{~m} \times 4 \mathrm{~m}$ were defined within each band. The experimental design was conditioned largely by the need to perform all agricultural works in the same direction and facilitate machinery traffic between plots. In the SCC trial, green pepper (Capsicum annuum L.) was transplanted on May 26, 2016, and on June 20, 2017.The last pepper harvest was on October 3, 2016, and on October 2, 2017. In ACC, savoy cabbage (Brassica oleracea var. sabauda L.) was transplanted on August 4, 2015, and on September 20, 2016. The last savoy cabbage harvest was carried out on December 2, 2015, and on February 22, 2017. In SCC, fertilization was carried out just after transplanting using a commercial organic fertilizer (i.e., $170 \mathrm{~kg} \mathrm{ha}^{-1} \mathrm{~N}$ ). In ACC, in both years, the fertilizer amount was the same $\left(100 \mathrm{~kg} \mathrm{ha}^{-1}\right.$ $\mathrm{N}$ ); however, in the first year, the fertilization was split in two applications (i.e., one just after transplanting and the other during the development of the cabbage), while in the second year, only one fertilization was carried out just after transplanting. In ACC, ASC was irrigated sprinklers in both years, while cabbage was watered according to the crop needs by using drip irrigation. In SCC, only the cash crop was dripirrigated according to the crop needs. In both trials, eight samples of $0.25 \mathrm{~m} \times 0.40 \mathrm{~m}$ were taken per plot. The samples were placed so that the corner of each sample leaned on a cash crop plant, and the longest side was placed perpendicular to the cash crop line.

\subsection{Statistical analysis}

We did not pool the raw data from different experiments because each trial had its own experimental design; instead, a 
specific statistical model was used for each trial. Then, we used a meta-analytic approach to test for the overall statistical support for the effect of ASC management on weed density and weed species richness.

Each statistical model included all the experimental variables evaluated in each specific trial (Table 1) to discount their effect in the dependent variable. Only termination (GM and ILRC), year (year 1 and year 2), and total dry biomass were explanatory variables common to all experiments. The first two were included as factors, whereas biomass was included as a covariate. Given the specifics of each trial, the year summarizes the variations in the cropping conditions caused by interannual variations in weather and timing and effectiveness of field operations, as well as differences in relation to changing the area within the field. We pooled the total dry biomass of the different ASCs included in each trial and the weeds present prior to the ASC termination. In the trials which included fertilization, the levels of this factor were defined specifically according to the description in Section 2.1.

In DK, EE, IT, and SI, linear mixed-effects models were used for each partner and year. The specific experimental layout of each trial, described in the previous section, defined the selection of the random effects for these trials.

In ES, the need to facilitate the machinery traffic between plots conditioned the experimental design. Thus, spatial correlation structures were introduced in ES models to account for the lack of independence between samples (Pinheiro et al. 2000). Models including the different classes of spatial correlation structures as well as a model without a spatial correlation structure were compared by likelihood ratio tests and by Akaike's information criterion (AIC) to establish the best model for each dependent variable and year.
When needed, data were transformed to meet the requirements of normality and homoscedasticity. Weed density was transformed applying logarithms (IT-SCC-pooled; ES-ACCpooled) and square root transformation (SI-SCC-pooled; ESSCC-pooled). Weed species richness was transformed applying logarithms (EE-SCC-1Y; EE-SCC-2Y). All statistical analyses were performed with $\mathrm{R}$ software (R Core Team 2017); for linear mixed-effect models, we used the lme function of the R nlme package (Pinheiro et al. 2017), while for ES models with spatial correlation structures, we used the gls function.

The meta-analytic approach was applied to analyze the effect across trials of the ASC management on weed density and weed species richness. This meta-analytic approach can be nearly as powerful as that based on combining data (Zaykin 2011). We used the weighted $Z$ test, which is essentially a weighted version of Stouffer's method:

$p_{Z}=1-\Phi\left(\frac{\sum_{i=1}^{k} w_{i} Z_{i}}{\sqrt{\sum_{i=1}^{k} w_{i}^{2}}}\right)$

where $Z_{i}=\Phi^{-1}\left(1-p_{i}\right) ; p_{i}$ is the $p$ value from the $i$ th study out of $k$ studies in total; $w_{i}$ is the weight selected for the study; and $\Phi$ and $\Phi^{-1}$ are the standard normal cumulative distribution function and its inverse, respectively. For this study, we weighted the $Z_{i}$ by the standardized effect size, as suggested by Zaykin (2011):

$w_{i}=\frac{\left|\mu_{i}\right|}{S E_{i}}$

where $\mu_{i}$ is the coefficient estimate and $\mathrm{SE}_{i}$ is its standard error. For testing the same alternative hypothesis, individual $p$ values were converted to one-sided before combining as follows (Zaykin 2011):

$p_{\text {one-sided }}=\left\{\begin{array}{c}\frac{p_{t w o-\text { sided }}}{2}, \text { if the direction of the effect coincides with the alternative hypothesis } \\ 1-\frac{p_{\text {two-sided }}}{2}, \text { otherwise }\end{array}\right.$

Independence among $p$ values is required for the weighted $Z$ test. Thus, we pooled the data from the two consecutive years in each trial to analyze the effect of the termination in each trial.

Community composition shifts were analyzed using permutational multivariate analysis of variance (PERMANOVA). Prior to PERMANOVA, we carried out the steps suggested by Anderson (2001): (i) we transformed the weed abundance measurements into presence/absence data; (ii) we used the Jaccard distance to compute the distances between plots; and (iii) we tested for homogeneity in multivariate dispersion with the betadisper function of the $\mathrm{R}$ package vegan (Oksanen et al. 2017). PERMANOVA was performed with the adonis function with the $\mathrm{R}$ package vegan (Oksanen et al. 2017). Specifically, it decomposes the variance of the distance matrices and attributes the components of the variance (i.e., measured as partial $R^{2}$ ) to the explanatory variables (i.e., factors and covariates).

The relative importance of the effect size of total dry biomass (ASCs + weeds), year, and termination was also 
calculated. For weed density and species richness, the estimated coefficient for each explanatory variable was divided by the intercept of the model (Armengot et al. 2015), while for the community composition, the effect size was related to the partial $R^{2}$ of each variable for each trail (Koricheva et al. 2013).

\section{Results and discussion}

\subsection{Effect of ILRC management on weed density, species richness, and community composition}

The ASC management had a clear effect on weed density, species richness, and community composition at the beginning of the cash crop (Table 2). ILRC management dramatically reduced weed density, and this effect was robust among trials. The mean across experiments showed that ILRC management reduced weed density by $35.1 \%$ in comparison with GM. In addition, analyzing both years pooled, the results of the meta-analysis showed that this trend was significant across trials (Fig. 2a). Specifically, ILRC reduced weed density at least in one of the two years in five (DK, EE, ES-SCC, ESACC, SI) out of the seven trials, and in two of them (DK, SI), this trend was significant in both years of experimentation (Fig. 2a). Previous field experiments in Italy have also reported a dramatic reduction in weed abundance in ILRC plots, averaging 86\% (Canali et al. 2013) and 83.5\% (Ciaccia et al. 2016) in comparison with GM. The pattern observed in our study could be related to the presence of mulch, which modifies the light and the temperature at the soil surface (Teasdale and Mohler 2000; Canali et al. 2013), both crucial factors affecting dormancy and germination of many weed species (Guillemin et al. 2013; Batlla and Benech-Arnold 2014).

Weed species richness also had a consistent response to ILRC management during the first 2 years of experimentation across trials (Table 2). ILRC management reduced species richness by $23.8 \%$ across trials, and this trend was significant according to the weighted Stouffer test (Fig. 2b). ILRC termination reduced weed species richness in at least one of the years of experimentation in all the countries except Italy, and in three of them (DK, EE, ES-ACC), this trend was significant in both years of experimentation (Fig. 2b). The immediate response observed after the adoption of ILRC management across trials diverged with the only study available so far (Halde et al. 2015), in which a significant response was observed in the fifth year of continuous management in arable rainfed crops. Furthermore, the consistent weed species richness reduction across trials observed in our study contrasts with previous studies. Positive and negative effects have been observed for the effects of tillage intensity (Nichols et al. 2015; Armengot et al. 2015) and the presence of mulch
(Campiglia et al. 2010; Radicetti et al. 2013) on weed species richness.

The general pattern observed for weed density and species richness under ILRC across trials contrasts with the local results of the trials carried out in Italy (i.e., ACC and SCC). In these trials, weed density and species richness were not reduced under ILRC management, and even a significant increase of weed density was noticed in the first and second year of experimentation of IT-ACC (Fig. 2a, b). The atypical pattern observed for weed density in IT-ACC trial could be related to the ASC and weed resprouting, while the absence of effect on weed species richness might be a consequence of the low levels of weed density in the experimental field where the trials were carried out (Table 2).

Analyzing weed species from the fourteen datasets, we observed that overall weed communities after the ASC management were dominated by annual and broadleaf species (Table 2). Weed community composition generally had a significant but low response to ASC management (ILRC vs. GM) in most of the trials analyzed. Specifically, in all the trials except in the Italian ACC, the composition of weed communities was significantly affected by the ASC management in both years of experimentation (Fig. 2c). Nonetheless, the percentage of weed community composition variability attributable to termination was generally low and ranged from a minimum value of $8.2 \%$ in the second year of the Italian SCC trial $(p=0.005)$ to a maximum of $34.3 \%$ in the second year of the trial in Slovenia $(p=0.001)$ (Fig. 2c). On the other hand, the average Jaccard distances between ASC managements (Table 2) indicate that the differences between ILRC plots are similar or even higher than between ILRC and GM plots. In all trials except the Italian ones, the ILRC plots were significantly more variable in weed composition than the GM ones. ILRC reduced drastically weed density and species richness, and this effect was rather unspecific, causing a strong divergence between samples, which means that ILRC does not select some species over others. Previous studies have reported changes in weed community composition produced by both tillage intensity changes (Nichols et al. 2015; Armengot et al. 2015) and mulch presence (Campiglia et al. 2010; Radicetti et al. 2013). However, as far as we know, only one study has considered the effect of ILRC management on weed community composition (Ciaccia et al. 2016). In this study, the authors speculate that ILRC could influence the weed community composition in organic vegetable cropping systems, but they did not statistically compare the differences between ILRC- and GM-managed plots.

In this study, weed density, species richness, and community composition were analyzed only at the early stages of crop growth. Nonetheless, some weed species might emerge later in the crop cycle due to the modifications of the soil 


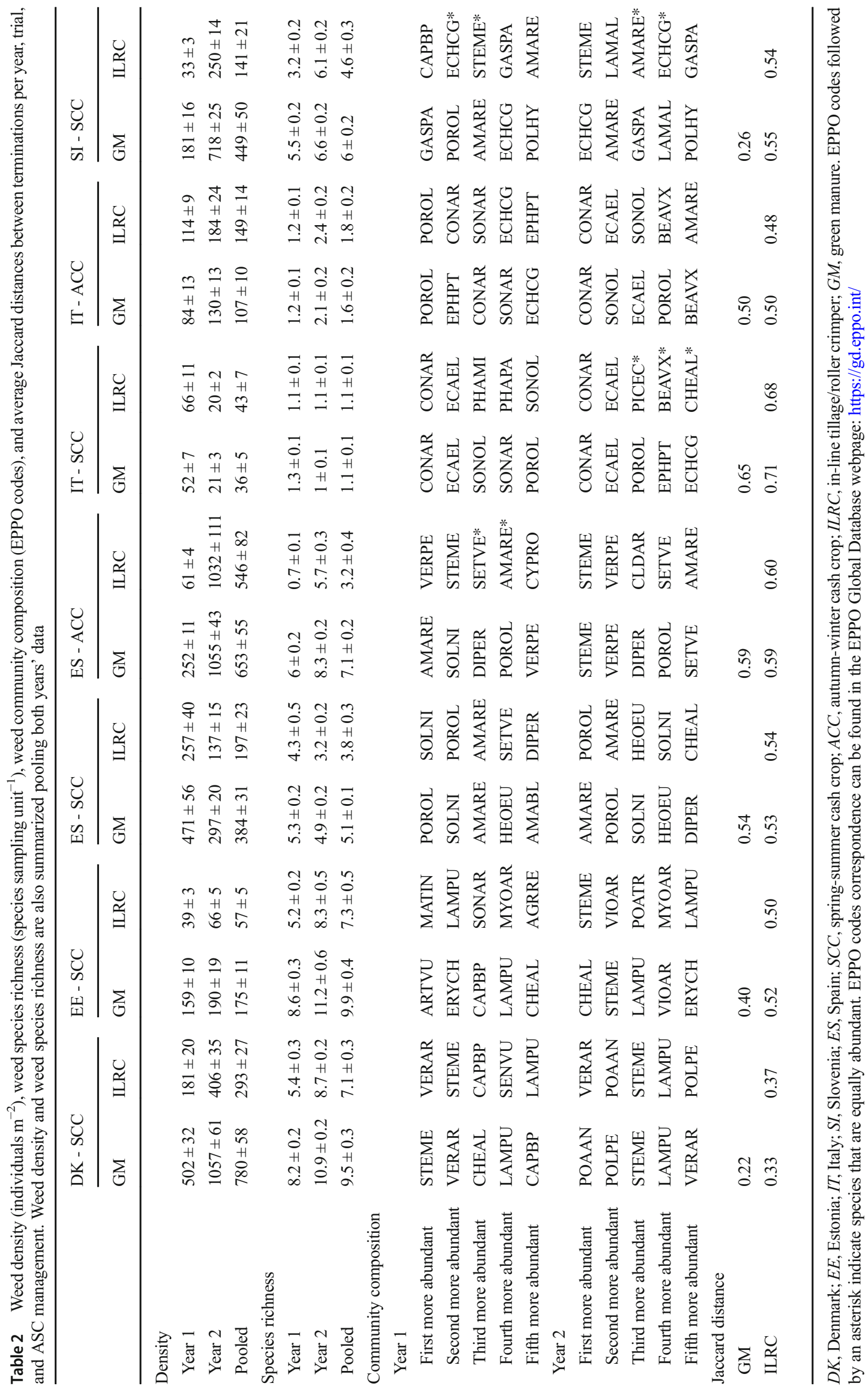


Fig. 2 a Percentage of weed density reduction in ILRC in comparison with GM. b Percentage of weed species richness reduction in $\mathrm{RC}$ in comparison with GM. c Community composition $\left(R^{2}\right)$. DK: Denmark, EE: Estonia, IT: Italy, SI: Slovenia, and ES: Spain. SCC: spring-summer cash crop; ACC: autumn-winter cash crop; ILRC: in-line tillage/roller crimper; GM: green manure. Significance codes: $* p \leq 0.05$; $* * p \leq 0.01 ; * * * p \leq 0.001$ a Percentage of weed density reduction in ILRC in comparison with GM

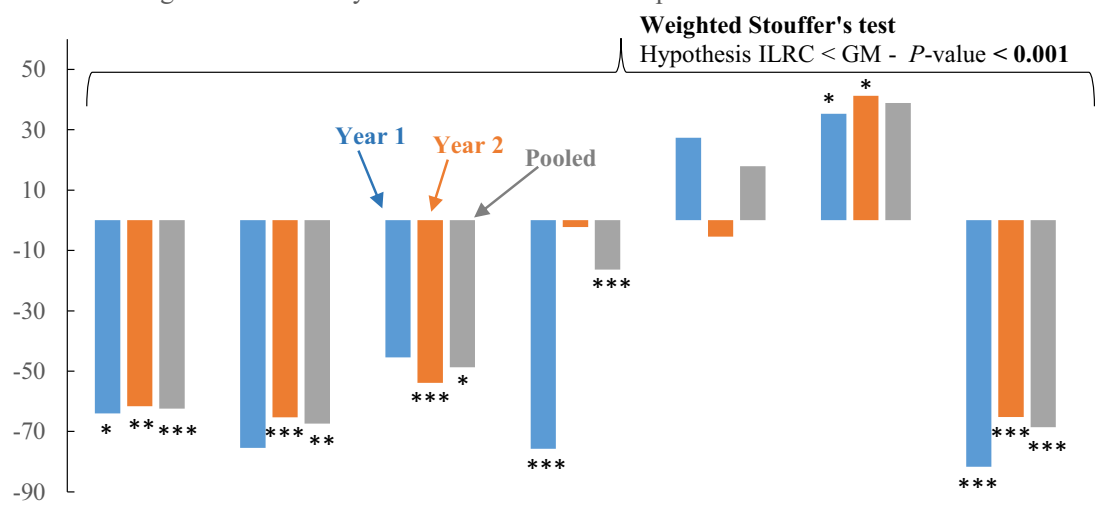

b Percentage of weed species richeness reduction in ILRC in comparison with GM

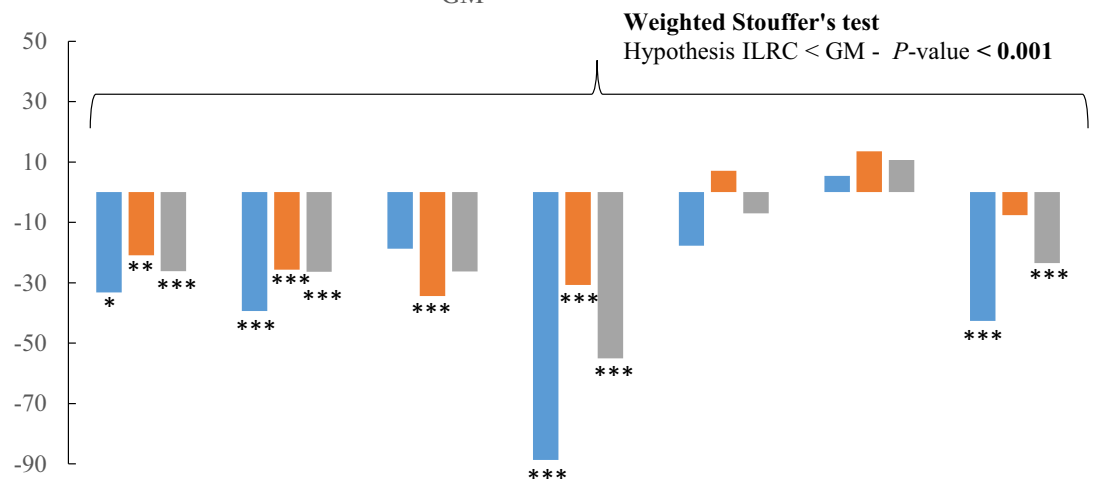

C Community composition $\left(\mathrm{R}^{2}\right)$

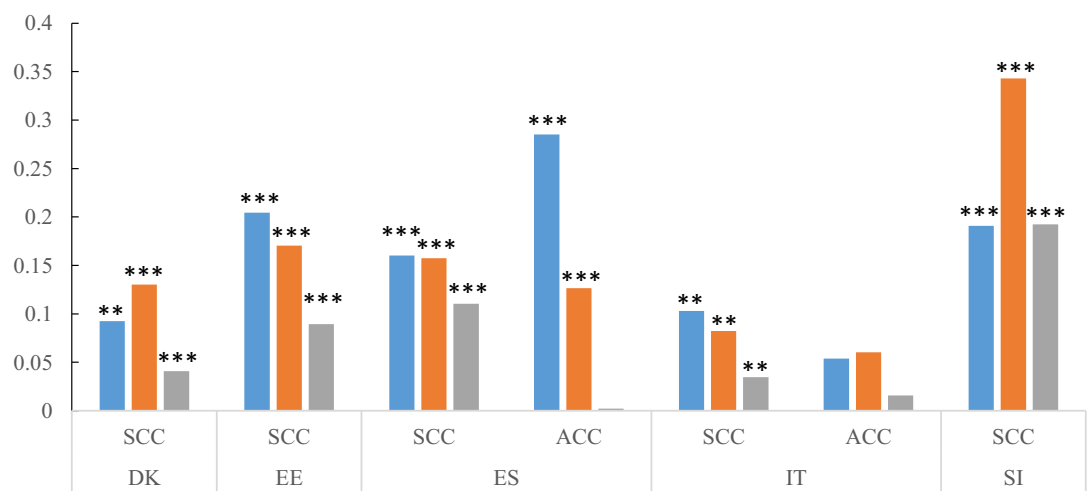

surface environment (Guillemin et al. 2013). These weeds could also compete for water and nutrients, and also cause problems during the harvest of some vegetables. Thus, this evaluation should be completed with studies analyzing the weed emergence and growth during the development. Additionally, ILRC long-term studies in vegetable systems are required to provide information on the cumulative effect of this technology over the years. According to previous studies focused on arable crops (Halde et al. 2015), one of the expected cumulative effects is the progressive establishment and proliferation of perennial weed species, which hinder the management of the cropping system and might affect cash crop yield.

\subsection{Effect size of the explanatory variables on structural parameters of weed communities}

Despite important implications from an agronomic point of view, there are no direct comparisons analyzing the relative importance of the explanatory variables (dry biomass, year, ASC management) in vegetable cropping systems using ASC. To fill this knowledge gap, in our study, we analyzed the effect size of the explanatory variables on structural parameter of weed communities (weed density, species richness, and community composition). We have found that the relative importance of the explanatory variables varied depending on the 
structural parameter of weed communities and the trial analyzed (Fig. 3).

ASC biomass flattened or chopped and incorporated into the soil is usually considered an important factor for controlling weeds (Radicetti et al. 2013; Canali et al. 2013; Ciaccia et al. 2016). However, in our study, the comparison of the size effects of the explanatory variables on weed density across trials reflected that the relative importance of total dry biomass was low in all cases (Fig. 3) despite the wide ranges of this variable and the different weed proportions in the total dry biomass managed across trials, years, and partners (Table 1). ASC management (ILRC vs. GM) and the variations in the cropping conditions (i.e., year) are more important than the biomass produced by the ASCs for weed density (Fig. 3).
Specifically, year had the largest effect size on weed density in four out of the seven trials evaluated. Thus, our results suggest that the reduction of weed density produced by ILRC management can be strongly affected by variations in cropping conditions. Previous studies have noticed a significant effect of both the year and ASC management on weed abundance under ILRC management, but the relative importance of each variable was neither analyzed nor discussed (Canali et al. 2013).

Some authors have suggested that community composition is mainly affected by the tillage intensity, while the weed species richness is a result of both the management and the environmental conditions (Nichols et al. 2015). Our results showed that both community composition and species
Fig. 3 Relative importance of the total dry biomass prior to ASC termination, the ASC management, and the year on the weed density, species richness, and community composition. For weed density and species richness, the estimate value of each variable was divided by the intercept of the model for each trial. In community composition, the $R^{2}$ was calculated for variable for each trial. DK: Denmark, EE: Estonia, IT: Italy, SI: Slovenia, and ES: Spain. SCC: springsummer cash crop; ACC: autumn-winter cash crop; ILRC: in-line tillage/roller crimper; GM: green manure
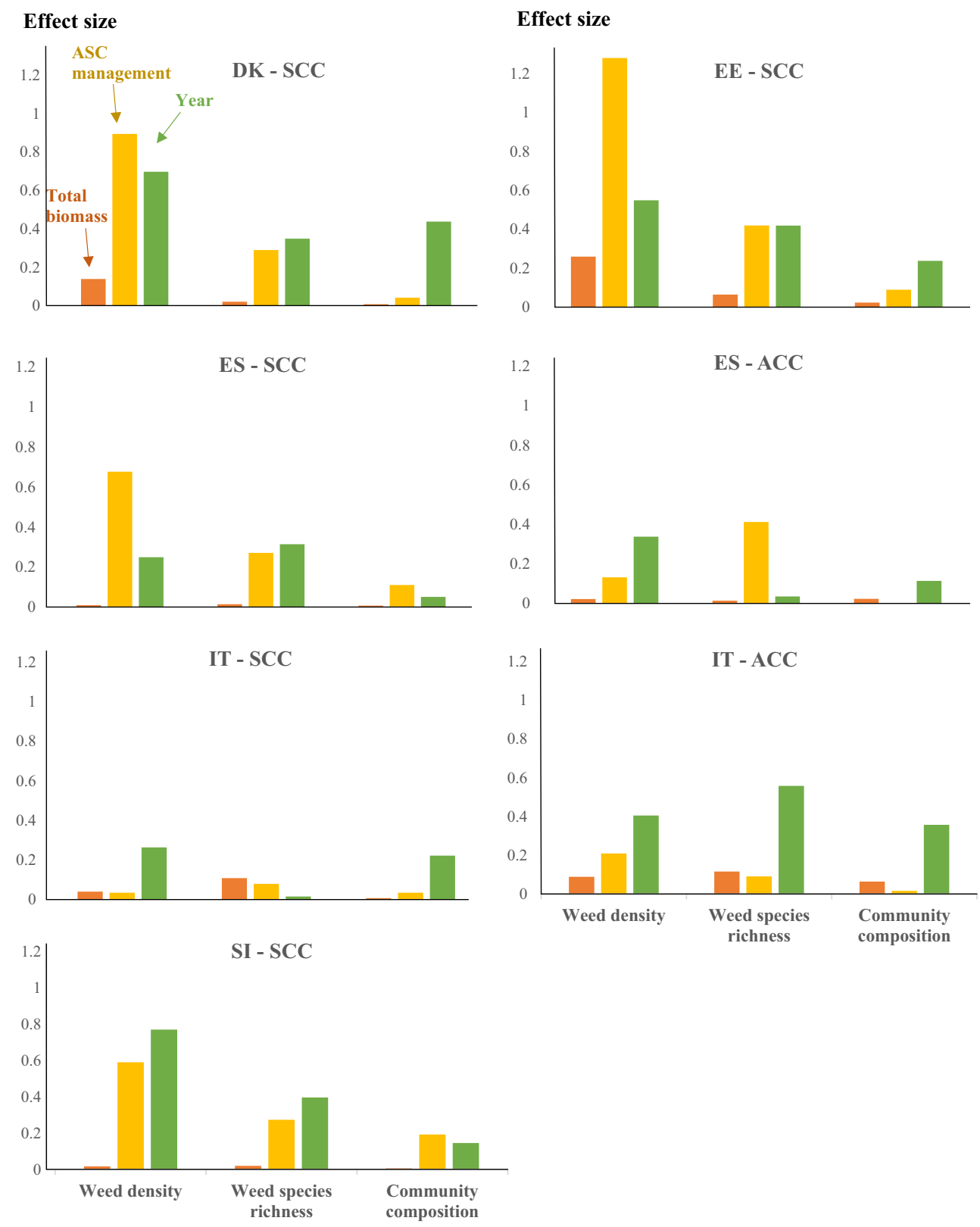

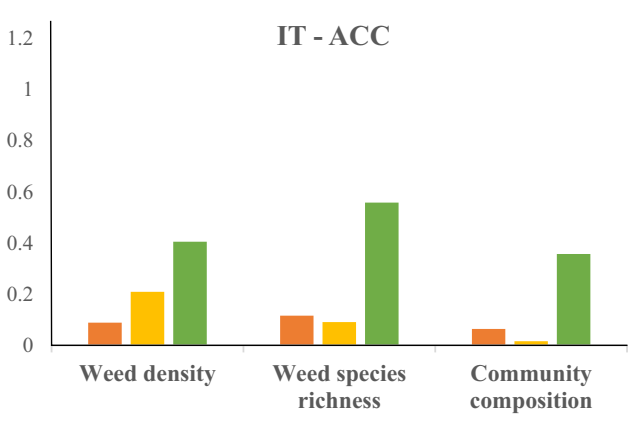


richness were influenced by the year and ASC management, and their relative importance varied across trials (Fig. 3). Nonetheless, the year had a larger effect size in more trials than ASC management both for weed species richness and community composition. Total dry biomass presented the lowest relative importance in all trials, except in IT-SCC for weed species richness.

Therefore, our study indicates, for the first time, that the variations in the cropping conditions can strongly affect the outcome of ASC management on the structural parameters of weed communities (weed density, species richness, and community composition). Furthermore, we also note that the effect of the flattened or green manured total dry biomass is less important than the effect of both ASC management and cropping conditions on weed density, species richness, and community composition for most of the trials analyzed.

\section{Conclusions}

This study, which includes fourteen datasets from five different countries across Europe, provides for the first time solid evidence of the effectiveness of ILRC management for weed control at early stages of crop growth in different vegetable systems, soils, and climatic conditions across Europe. However, most importantly, although the benefits of ILRC management can be strongly affected by variations in cropping conditions (including but not restricted to interannual weather conditions, timing and effectiveness of field operations, variations between fields), our results provide a successful example that can contribute to reduce the reliance on tillage for weed management in organic vegetable systems.

Our multisite study also contributes to reduce the knowledge gap existing in the literature regarding the impact of ILRC management on weed species richness and community composition. We document for the first time a general trend under ILRC management of reduced weed species richness in seven trials across Europe in the transition to this management technique. Additionally, we report a significant but generally low effect of ASC management on weed community composition in most of the trials analyzed. Furthermore, we note that the effect of the total dry biomass, either flattened or used as green manure, is less important than the effect of both ASC management and the yearly conditions on weed density, species richness, and community composition for most of the trails analyzed.

Further research is required to identify the effect of the presence of mulch in ILRC systems on the environmental conditions of the soil surface, in different soils and climatic conditions across Europe, and how it affects the emergence of weeds along the cash crop cycle. Additionally, before this strategy can be suggested to farmers as a continuous management to be followed along the years, long-term studies analyzing the effect of this technology in the weed community composition would be required.

Authors' contributions David Navarro-Miró contributed to the design of the work, collected and analyzed the data, interpreted the results, and drafted the article. José M. Blanco-Moreno contributed to the analysis of data, the interpretation of the results, and the drafting of the article. Corrado Ciaccia contributed to the conception and design of the work and collected and analyzed data. Lourdes Chamorro, Hanne Lakkenborg Kristensen, Margita Hefner, Kalvi Tamm, Elena Testani, Ingrid Bender, Urška Lisec, Martina Bavec, Hélène Vedie, and Līga Lepse contributed to the design and management of the experiments and collection of data in each country. Stefano Canali (SoilVeg project coordinator) conceived the trans-national, multisite, and multi-season dimension of the entire experiment. F. Xavier Sans had a major role in the conception and design of the work, data analysis, and interpretation of the results and contributed to drafting the article. All the authors critically revised the final manuscript.

Funding information The project SoilVeg (http://projects.au.dk/ coreorganicplus/research-projects/soilveg/) is funded by ERA-Net CORE Organic Plus Funding Bodies partners of the European Union's FP7 research and innovation program under the grant agreement no. 618107. DNM was funded by a PhD grant from the Ministerio de Educación, Cultura y Deporte from Spain (FPU14/03868).

\section{Compliance with ethical standards}

Conflict of interest The authors declare that they have no conflicts of interest.

Disclaimer The findings and conclusions expressed in this paper are those of the authors and do not reflect the views of the Ministerio de Educación, Cultura y Deporte of Spain, or any of the EU funding bodies.

\section{References}

Altieri MA, Lana MA, Bittencourt HV et al (2011) Enhancing crop productivity via weed suppression in organic no-till cropping systems in Santa Catarina, Brazil. J Sustain Agric 35:855-869. https://doi.org/ 10.1080/10440046.2011.588998

Anderson MJ (2001) A new method for non-parametric multivariate analysis of variance. Austral Ecol 26:32-46. https://doi.org/10. 1111/j.1442-9993.2001.01070.pp.x

Armengot L, Berner A, Blanco-Moreno JM et al (2015) Long-term feasibility of reduced tillage in organic farming. Agron Sustain Dev 35: 339-346. https://doi.org/10.1007/s13593-014-0249-y

Batlla D, Benech-Arnold RL (2014) Weed seed germination and the light environment: implications for weed management. Weed Biol Manag 14(2):77-87. https://doi.org/10.1111/wbm.12039

Campiglia E, Mancinelli R, Radicetti E, Caporali F (2010) Effect of cover crops and mulches on weed control and nitrogen fertilization in tomato (Lycopersicon esculentum Mill.). Crop Prot 29:354-363. https://doi.org/10.1016/J.CROPRO.2009.12.001

Canali S, Campanelli G, Ciaccia C et al (2013) Conservation tillage strategy based on the roller crimper technology for weed control in Mediterranean vegetable organic cropping systems. Eur J Agron 50: 11-18. https://doi.org/10.1016/J.EJA.2013.05.001

Canali S, Diacono M, Campanelli G, Montemurro F (2015) Organic notill with roller crimpers: agro-ecosystem services and applications in organic Mediterranean vegetable productions. Sustain Agric Res 4: 70. https://doi.org/10.5539/sar.v4n3p70 
Carr PM, Anderson RL, Lawley YE et al (2012) Organic zero-till in the northern US Great Plains Region: opportunities and obstacles. Renew Agric Food Syst 27:12-20. https://doi.org/10.1017/ S174217051100041X

Casagrande M, Peigné J, Payet V et al (2016) Organic farmers' motivations and challenges for adopting conservation agriculture in Europe. Org Agric 6:281-295. https://doi.org/10.1007/s13165015-0136-0

Ciaccia C, Canali S, Campanelli G et al (2016) Effect of roller-crimper technology on weed management in organic zucchini production in a Mediterranean climate zone. Renew Agric Food Syst 31:111-121. https://doi.org/10.1017/S1742170515000046

Ciaccia C, Testani E, Campanelli G et al (2015) Ecological service providing crops effect on melon-weed competition and allelopathic interactions. Org Agric 5:199-207. https://doi.org/10.1007/s13165014-0088-9

Frasconi C, Martelloni L, Antichi D et al (2019) Combining roller crimpers and flaming for the termination of cover crops in herbicide-free no-till cropping systems. PLoS One 14:e0211573. https://doi.org/10.1371/journal.pone.0211573

Gallandt E (2014) Weed management in organic farming. In: Recent advances in weed management. Springer New York, New York, pp 63-85

Guillemin JP, Gardarin A, Granger S et al (2013) Assessing potential germination period of weeds with base temperatures and base water potentials. Weed Res 53:76-87. https://doi.org/10.1111/wre.12000

Halde C, Bamford KC, Entz MH (2015) Crop agronomic performance under a six-year continuous organic no-till system and other tilled and conventionally-managed systems in the northern Great Plains of Canada. Agric Ecosyst Environ 213:121-130. https://doi.org/10. 1016/j.agee.2015.07.029

Koricheva J, Gurevitch J, Mengersen KL (2013) Handbook of metaanalysis in ecology and evolution. Princeton University Press ISBN 9781400846184

Luna JM, Mitchell JP, Shrestha A (2012) Conservation tillage for organic agriculture: evolution toward hybrid systems in the western USA. Renew Agric Food Syst 27:21-30. https://doi.org/10.1017/ S1742170511000494

Mäder P, Berner A (2012) Development of reduced tillage systems in organic farming in Europe. Renew Agric Food Syst 27:7-11. https://doi.org/10.1017/S1742170511000470

Metzger MJ, Bunce RGH, Jongman RHG et al (2005) A climatic stratification of the environment of Europe. Glob Ecol Biogeogr 14(6): 549-563. https://doi.org/10.1111/j.1466-822x.2005.00190.x

Mirsky SB, Ryan MR, Curran WS et al (2012) Conservation tillage issues: cover crop-based organic rotational no-till grain production in the mid-Atlantic region, USA. Renew Agric Food Syst 27:31-40. https://doi.org/10.1017/S1742170511000457

Moonen AC, Bàrberi P (2004) Size and composition of the weed seedbank after 7 years of different cover-crop-maize management systems. Weed Res 44:163-177. https://doi.org/10.1111/j.13653180.2004.00388.x

Nichols V, Verhulst N, Cox R, Govaerts B (2015) Weed dynamics and conservation agriculture principles: a review. Field Crop Res 183: 56-68. https://doi.org/10.1016/j.fcr.2015.07.012

Oksanen J, Blanchet FG, Friendly M, et al (2017) vegan: Community Ecology Package. R package version 2.4-5. https:/CRAN.Rproject.org/package=vegan

Peigné J, Casagrande M, Payet V et al (2016) How organic farmers practice conservation agriculture in Europe. Renew Agric Food Syst 31:72-85. https://doi.org/10.1017/S1742170514000477

Pinheiro J, Bates D, DebRoy S, Sarkar D and R Core Team (2017). nlme: Linear and Nonlinear Mixed Effects Models. R package version 3.1131. https://CRAN.Rproject.org/package=nlme

Pinheiro J, Bates D, Douglas M (2000) Mixed-effects models in S and SPLUS. Springer-Verlag, New York

Radicetti E, Mancinelli R, Campiglia E (2013) Impact of managing cover crop residues on the floristic composition and species diversity of the weed community of pepper crop (Capsicum annuum L.). Crop Prot 44:109-119. https://doi.org/10.1016/J.CROPRO.2012.10.017

R Core Team (2017) R: A language and environment for statistical computing. R Foundation for Statistical Computing, Vienna https:// www.R-project.org/

Sapkota TB, Mazzoncini M, Bàrberi P et al (2012) Fifteen years of no till increase soil organic matter, microbial biomass and arthropod diversity in cover crop-based arable cropping systems. Agron Sustain Dev 32:853-863. https://doi.org/10.1007/s13593-011-0079-0

Teasdale JR, Mohler CL (2000) The quantitative relationship between weed emergence and the physical properties of mulches. Weed Sci 48:385-392. https://doi.org/10.1614/0043-1745(2000)048[0385: TQRBWE]2.0.CO;2

Vincent-Caboud L, Peigné J, Casagrande M, Silva E (2017) Overview of organic cover crop-based no-tillage technique in Europe: farmers' practices and research challenges. Agriculture 7:42. https://doi.org/ 10.3390/agriculture7050042

Zaykin DV (2011) Optimally weighted Z-test is a powerful method for combining probabilities in meta-analysis. J Evol Biol 24:18361841. https://doi.org/10.1111/j.1420-9101.2011.02297.x 